\title{
Safety and tolerability of sustained exogenous ketosis using ketone monoester drinks for 28 days in healthy adults
}

\author{
Adrian Soto-Mota*, Hannah Vansant, Rhys D. Evans, Kieran Clarke \\ Department of Physiology, Anatomy and Genetics, University of Oxford, Oxford, United Kingdom
}

\section{A R T I C LE IN F O}

\section{Keywords}

Ketone monoester

Ketone bodies

Safety

Tolerability

Toxicity

\begin{abstract}
A B S T R A C T
Throughout history, the only way humans could raise their blood ketone levels was by several days of fasting or by following a strict low-carb, high-fat diet. A recently developed, dietary source of ketones, a ketone monoester, elevates D- $\beta$-hydroxybutyrate $(\beta \mathrm{HB})$ to similar concentrations within minutes, with $\beta \mathrm{HB}$ remaining raised for several hours. To date, the longest human safety study of the exogenous ketone ester was for 5 days, but longer consumption times may be desired. Here we report results for 24 healthy adults, aged 18-70 years, who drank $25 \mathrm{ml}(26.8 \mathrm{~g}$ ) of the ketone monoester, $(R)$-3-hydroxybutyl $(R)$-3-hydroxybutyrate, three times a day for 28 days (a total of $2.1 \mathrm{~L}$ ). Anthropomorphic measurements, plus fasting blood and urine analyses were made weekly. It was found that elevating blood $\beta \mathrm{HB}$ concentrations from 0.1 to $4.1( \pm 1.1) \mathrm{mM}$ three times a day for 28 days had no effect on body weights or composition, fasting blood glucose, cholesterol, triglyceride or electrolyte concentrations, nor blood gases or kidney function, which were invariably normal. Mild nausea was reported following 6 of the 2,016 drinks consumed. We conclude that sustained exogenous ketosis using a ketone monoester is safe and well-tolerated by healthy adults.
\end{abstract}

\section{Introduction}

An exogenous, rapidly available, alternative energy source to fatty acids or carbohydrates may alleviate the metabolic abnormalities that underlie many human diseases. The ketone bodies, D-beta-hydroxybutyrate $(\beta \mathrm{HB})$ and acetoacetate, are not readily available in the human diet, but are produced in the liver from free fatty acids in response to low blood glucose and insulin levels, as an alternative to glucose as an energy supply for the brain (Newman and Verdin, 2014). Until recently, blood ketones could only be raised over several days by fasting or by strictly following low-carb, high-fat diets. Similar blood $\beta \mathrm{HB}$ concentrations can now be attained within 30 min by drinking the ketone monoester, (R)-3-hydroxybutyl (R)-3-hydroxybutyrate, which introduces a new metabolic state, termed exogenous nutritional ketosis (Cox et al., 2016). The ketone monoester provides only the $\mathrm{D}$ form of $\beta \mathrm{HB}$ and is salt-free (Clarke et al., 2012b). As many chronic diseases are characterised or worsened by metabolic abnormalities, an additional and highly efficient fuel opens potential applications, for example in diabetes (Mizuno et al., 2017), Parkinson's disease (Norwitz et al., 2019), Alzheimer's disease (Murray et al., 2016; Newport et al., 2015) and epilepsy (Gano et al., 2014), for which a ketogenic diet has positive effects (Veech, 2004). Such chronic diseases would require consumption of the ketone ester daily for many days. To date, the continuous consumption of (R)-3-hydroxybutyl ( $R$ )-3-hydroxybutyrate has been monitored in two rat studies (during gestation and for twenty-eight days (Clarke et al., 2012a)), and in two human studies (3 drinks/day for five days (Clarke et al., 2012b) and 2 drinks/day for three weeks (Poffé et al., 2019)). Most other studies report single-drink acute effects, such as decreased circulating fatty acid and glucose concentrations (Cox et al., 2016; Kemper et al., 2015; Stubbs et al., 2017). Here, we demonstrate the safety and tolerability of sustained exogenous ketosis, using three ketone monoester drinks per day for 28 consecutive days $(2.1 \mathrm{~L} /$ participant), in both athletes and sedentary adults as part of their normal, daily routine.

\section{Materials and methods}

\subsection{Ethics approval}

This study was preregistered (ISRCTN12401551) and the protocol, including amendments and consent forms, was approved by the South Central, Oxford B Research Ethics Committee (18/SC/0064). This study was conducted in accordance with the guidelines set forth by the

\footnotetext{
Abbreviations: $\beta \mathrm{HB}, \mathrm{D}-\beta$-hydroxybutyrate; HOMA-IR, Homeostatic model assessment for insulin resistance; HDL, High density lipoprotein; Apo-B, Apolipoprotein B; HbA1c, Glycated haemoglobin.

* Corresponding author. Department of Physiology, Anatomy and Genetics, Sherrington Building University of Oxford, Parks Road, Oxford, OX1 3PT, United Kingdom.

E-mail address: adrian.soto@dpag.ox.ac.uk (A. Soto-Mota)
} 
International Conference on Harmonisation Guidelines for Good Clinical Practice, and the Declaration of Helsinki regarding the treatment of human subjects in a study.

\subsection{Study design}

The aim of this study was to determine whether drinking $75 \mathrm{ml}$ ( $80.5 \mathrm{~g}$ ) ketone ester, each day for 28 days, was safe for healthy adult humans, irrespective of age, gender or body weight. Twenty-four volunteers evenly distributed according to age (18-70 years), body weight $(50-103 \mathrm{~kg}$ ) and sex, consumed $25 \mathrm{ml}$ of the ketone monoester, (R)-3-hydroxybutyl (R)-3-hydroxybutyrate, three times a day for 28 days. The participants were asked to measure out $25 \mathrm{ml}$ of the ester in a measuring cup then drink it either neat (100\% pure ketone ester) or after diluting with artificially sweetened commercially available drink. The ketone monoester is a clear, slightly viscous liquid having a density of $1.0731 \mathrm{~g} /$ $\mathrm{ml}$ at $22^{\circ} \mathrm{C}$, so $25 \mathrm{ml}$ weighed $26.8 \mathrm{~g}$.

Nine of the volunteers, 3 women and 6 men, usually exercised for more than $12 \mathrm{~h}$ per week and continued to do so during their participation ("athletes"). Three of the male athletes were consuming a ketogenic diet when recruited to the study, so continued with their diet when drinking the ketone monoester. To elevate $\beta \mathrm{HB}$ blood levels for at least $12 \mathrm{~h}$ every day, participants were instructed to allow at least $4 \mathrm{~h}$ between drinks and to keep a daily diary, recording diet, activity and symptoms (both positive and negative) using open questions.

To detect the most likely highest $\beta \mathrm{HB}$ concentrations reached, participants recorded their blood $\beta \mathrm{HB}$ and glucose concentrations weekly, immediately before and 30 min following their third drink on their least active day using Abbot OptiumNeo ${ }^{\circledR}$ meters.

The volunteers attended the clinic on a weekly basis for anthropomorphic measurements and to provide blood and urine samples. Body composition was measured using four-point bioelectrical impedance $(\mathrm{BF} 508 \AA$, Omron Electronics Ltd, Milton Keynes, England, United Kingdom). Each week, blood samples were analysed for $\mathrm{pH}$, gases, electrolytes, glucose, haemoglobin, serum creatinine and urea (Abbot isTAT $®$ cartridges CG4 \pm and CHEM8 \pm , Abbot Point of Care Inc, Princeton, New Jersey, USA). Urine was analysed for bilirubin, blood, leukocytes, glucose, ketones, nitrite, $\mathrm{pH}$, protein, specific gravity, and urobilinogen (Bayer Multistix ${ }^{\circledR}$ Reagent Strips for Urinalysis, Bayer HealthCare LLC, Elkhart, IN, USA).

\subsection{Statistical analysis}

Data, presented as means \pm standard deviations, were analysed using a two-tailed paired Student's t-test. Differences were considered significant at $\mathrm{p}<0.05$.

\section{Results}

All 24 participants finished the study with a reported adherence of $>90 \%$. Fig. 1 shows that age and gender were evenly distributed throughout the cohort. Drinking three ketone monoester drinks a day $(75 \mathrm{ml})$ for 28 days $(2.1 \mathrm{~L}$ /person) had no effect on body weights, body mass indices or body composition in either men (age $45 \pm 20$ years) or women (age $40 \pm 16$ years) (Table 1 ).

At weekly intervals, participants recorded their own non-fasting blood $\beta \mathrm{HB}$ and glucose concentrations immediately before, and $30 \mathrm{~min}$ after, a ketone drink. The maximum $\beta \mathrm{HB}$ concentration reached by each participant, shown in Fig. 2, demonstrates that a range of $\beta \mathrm{HB}$ concentrations, from 1.8 to $6.3 \mathrm{mM}$, were reached after drinking $25 \mathrm{ml}$ ketone ester. Over four weeks, the average minimum blood $\beta \mathrm{HB}$ was $0.1 \pm 0.01 \mathrm{mM}$ and the average maximum was $4.1 \pm 1.1 \mathrm{mM}$ (Table 2). Because each participant consumed $25 \mathrm{ml}$ of ketone ester, the weight-adjusted volume of ester consumed in each drink range from 0.24

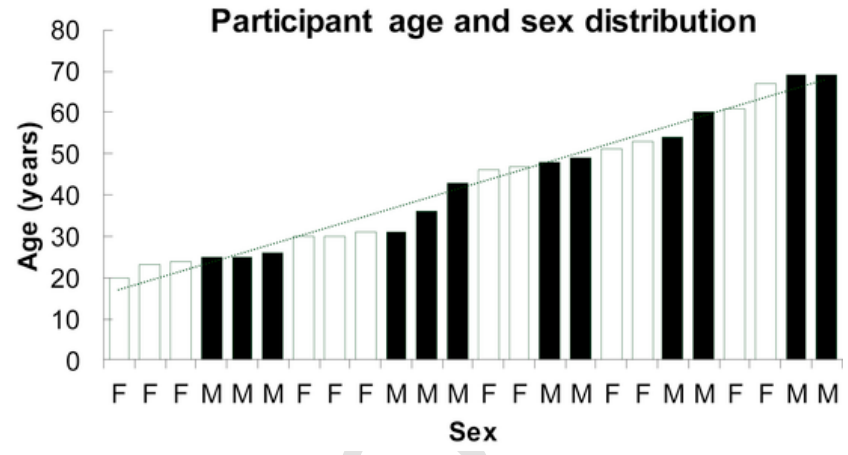

Fig. 1. Participants $(n=24)$ were aged between 20 and 69 years, with the 12 women (white) and 12 men (black) evenly distributed according to age.

Table 1

Body weights, body mass indices (BMI) and body composition for men and women before and following 28 days of ketone monoester drinks $(3 \times 25 \mathrm{ml} /$ day $)$.

\begin{tabular}{|c|c|c|c|c|}
\hline & \multicolumn{2}{|c|}{ Before ketone drinks } & \multicolumn{2}{|c|}{$\begin{array}{l}\text { After 28-days of ketone } \\
\text { drinks }\end{array}$} \\
\hline & $\begin{array}{l}\text { Men } \\
(\mathrm{n}=12)\end{array}$ & $\begin{array}{l}\text { Women } \\
(\mathrm{n}=12)\end{array}$ & $\begin{array}{l}\text { Men } \\
(n=12)\end{array}$ & $\begin{array}{l}\text { Women } \\
(\mathrm{n}=12)\end{array}$ \\
\hline $\begin{array}{l}\text { Body weights } \\
(\mathrm{kg})\end{array}$ & $86.7 \pm 12.6$ & $64.2 \pm 12.2$ & $85.3 \pm 12.1$ & $64.5 \pm 12.3$ \\
\hline BMI $\left(\mathrm{kg} / \mathrm{m}^{2}\right)$ & $27.0 \pm 4.4$ & $23.5 \pm 4.1$ & $26.8 \pm 4.5$ & $23.6 \pm 4.1$ \\
\hline $\begin{array}{l}\text { Composition (\% } \\
\text { fat) }\end{array}$ & $22.8 \pm 7.8$ & $30.3 \pm 8.1$ & $22.6 \pm 7.4$ & $30.6 \pm 4.9$ \\
\hline
\end{tabular}

Data are means \pm standard deviation

to $0.50 \mathrm{mg} / \mathrm{kg}$ (Fig. 2), or total daily intake of between 0.72 and $1.5 \mathrm{mg}$ / $\mathrm{kg}$ body weight per day. There was no relation between body weight and the $\beta \mathrm{HB}$ levels reached (Fig. 2). The three participants consuming the ester in addition to a ketogenic diet had the same $\beta \mathrm{HB}$ concentrations as those consuming a normal, balanced diet.

Drinking $2.1 \mathrm{~L}$ of ketone monoester over 28 days had no effect on body weights, body composition, blood $\mathrm{pH}$ (metabolic acidosis), $\mathrm{HCO}_{3}^{-}$, electrolyte, or metabolite concentrations (Table 3). There was no evidence of acute kidney injury or urinary bleeding, and urinary $\mathrm{pH}$, specific gavity, glucose, leukocytes, nitrite, protein and urobilinogen were invariably normal.

Fasting blood samples, taken at the start and end of the 28 days, showed normal circulating glucose, triglycerides, cholesterol, HDL, ApoB, HbA1c and C-reactive protein (Table 4).

The most frequently reported adverse event was mild nausea shortly following 6 of the 2,016 drinks consumed, a mild headache was reported 3 times (3/2,016 drinks) and mild diarrhoea and mild abdominal pain were each reported by two participants (Table 5 ). Thus, $0.75 \%$ of drinks $(14 / 2,016)$ may be expected to result in a mild adverse event.

\section{Discussion}

The most important finding of this study was that sustained exogenous ketosis for 28 days was safe for healthy adults in that it had no effect on any physical, blood or urine parameter, and was independent of age, level of physical activity and diet. It was found that a $25 \mathrm{ml}$ drink of ketone ester increased blood $\beta \mathrm{HB}$ concentrations to between 1.8 and $6.3 \mathrm{mM}$, the increase being independent of body weight, gender or routine diet. Such a variable $\beta \mathrm{HB}$ increase suggests that other factors, such as physical activity and prior food consumption, have considerable influence over the $\beta \mathrm{HB}$ concentrations that can be attained (Stubbs et al., 2017). Previous pharmacokinetic studies of the ketone 


\section{Blood $\beta \mathrm{HB}$ concentrations $\mathbf{3 0}$ min after a ketone ester drink}

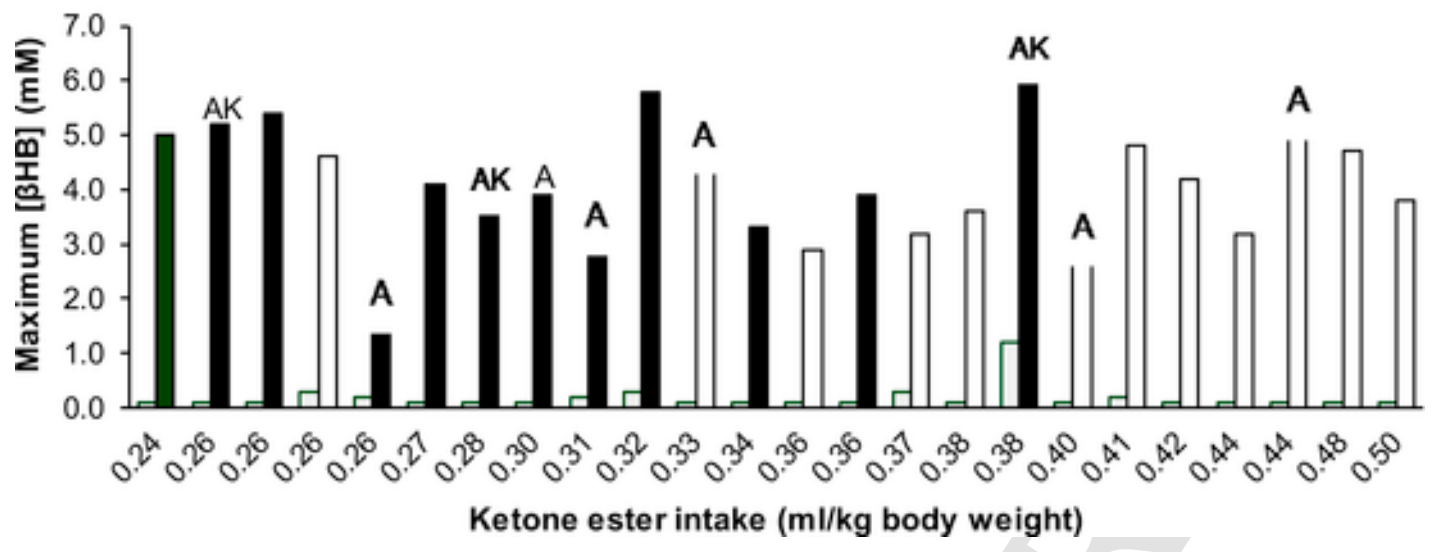

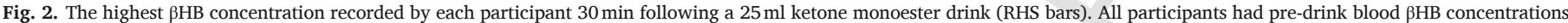

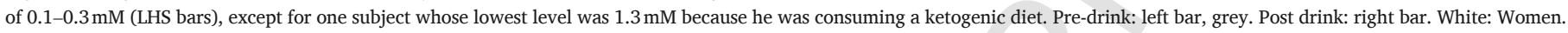
Black: Men. A: Athlete. AK: Athlete consuming a ketogenic diet.

Table 2

Random, non-fasting whole blood $\beta \mathrm{HB}$ and glucose concentrations measured before and $30 \mathrm{~min}$ following a $25 \mathrm{ml}$ drink of ketone monoester $(\mathrm{n}=24)$.

\begin{tabular}{lllll}
\hline & Week 1 & Week 2 & Week 3 & Week 4 \\
\hline$\beta$ HB pre-drink (mM) & $0.1 \pm 0.01$ & $0.1 \pm 0.02$ & $0.1 \pm 0.01$ & $0.1 \pm 0.01$ \\
$\beta$ HB post-drink (mM) & $4.3 \pm 1.1^{*}$ & $3.9 \pm 1.0^{*}$ & $4.1 \pm 1.1^{*}$ & $3.9 \pm 1.0^{*}$ \\
$\begin{array}{l}\text { Glucose pre-drink (mM) } \\
\text { Glucose post-drink }\end{array}$ & $5.3 \pm 0.6$ & $5.4 \pm 0.6$ & $5.4 \pm 0.4$ & $5.0 \pm 0.5$ \\
$(\mathrm{mM})$ & $5.0 \pm 0.4$ & $5.2 \pm 0.3$ & $5.1 \pm 0.6$ & $4.8 \pm 0.4$ \\
\hline
\end{tabular}

Data are means \pm standard deviation. ${ }^{*} \mathrm{P}<0.001$.

monoester have reported much tighter increases in $\beta \mathrm{HB}$ concentrations, but under highly controlled, reproducible conditions following a single drink (Clarke et al., 2012a; Cox et al., 2016; Shivva et al., 2016). Here, we determined the safety of $\beta \mathrm{HB}$ under the uncontrolled conditions of everyday normal adult life, which resulted in highly variable $\beta \mathrm{HB}$ concentrations that probably occur when the ketone monoester is consumed, it being available for purchase by athletes in the US in diluted form ( $25 \mathrm{ml}$ ketone monoester made up to $65 \mathrm{ml}$ ).
The maximum $\beta \mathrm{HB}$ concentration attained was $6.3 \mathrm{mM}$ from a pre-drink level of $1.2 \mathrm{mM}$ in one of the three athletes who was following a ketogenic diet (Fig. 2), little higher than in those on a normal diet, which was probably because exogenous $\beta \mathrm{HB}$ inhibited lipolysis (i.e. endogenous ketosis is inhibited when exogenous ketone levels are high) (Taggart et al., 2005).

The ketone ester was well-tolerated given the high adherence of the participants, both to consumption of the drink and record keeping, so the low frequency and intensity of adverse effects were not due to missed drinks or poor recording. As most of the participants worked in healthcare or were athletes, it is unlikely that adherence of the general population would be as high.

Children with epilepsy who are placed on a ketogenic diet to control seizures have an increased risk of nephrolithiasis (Kielb et al., 2000), which is monitored using dipstick detection of urinary blood. Using the same method, we found no evidence for nephrolithiasis in adults with sustained exogenous ketosis over 28 days. All participants had normal blood $\mathrm{pH}$ and electrolyte levels which suggests that

Table 3

Effects of drinking $3 \times 25 \mathrm{ml}$ ketone ester drinks/day for 28 days $(\mathrm{n}=24)$ on body weights and composition plus whole blood and urine biochemistry.

\begin{tabular}{|c|c|c|c|c|c|}
\hline Body measurements & Baseline (fasting) & Week 1 (non-fasting) & Week 2 (non-fasting) & Week 3 (non-fasting) & Week 4 (fasting) \\
\hline Weight $(\mathrm{kg})$ & $75 \pm 16$ & $75 \pm 15$ & $75 \pm 16$ & $75 \pm 15$ & $74 \pm 15^{*}$ \\
\hline Composition (percent fat) (\%) & $26.4 \pm 8.9$ & $25.8 \pm 8.1$ & $25.8 \pm 8.7$ & $24.4 \pm 7.3$ & $25.3 \pm 9.1$ \\
\hline \multicolumn{6}{|l|}{ Whole blood measurements } \\
\hline $\mathrm{pH}$ & $7.36 \pm 0.02$ & $7.36 \pm 0.04$ & $7.37 \pm 0.02$ & $7.35 \pm 0.03$ & $7.37 \pm 0.02$ \\
\hline $\mathrm{HCO}^{-}{ }_{3}(\mathrm{mM})$ & $27 \pm 2$ & $28 \pm 2$ & $26 \pm 2$ & $26 \pm 3$ & $27 \pm 3$ \\
\hline $\mathrm{Na}^{+}(\mathrm{mM})$ & $141 \pm 1$ & $140 \pm 2$ & $140 \pm 1$ & $140 \pm 2$ & $141 \pm 2$ \\
\hline $\mathrm{K}^{+}(\mathrm{mM})$ & $3.9 \pm 0.2$ & $4.0 \pm 0.2$ & $4.0 \pm 0.3$ & $4.0 \pm 0.2$ & $4.0 \pm 0.2$ \\
\hline $\mathrm{Cl}^{-}(\mathrm{mM})$ & $102 \pm 2$ & $100 \pm 2$ & $100 \pm 2$ & $101 \pm 3$ & $102 \pm 3$ \\
\hline $\mathrm{Ca}^{2+}(\mathrm{mM})$ & $1.20 \pm 0.03$ & $1.25 \pm 0.05$ & $1.24 \pm 0.04$ & $1.24 \pm 0.07$ & $1.21 \pm 0.05$ \\
\hline Anion Gap & 16 & 18 & 18 & 17 & 18 \\
\hline Hemoglobin $(g / L)$ & $14.3 \pm 1.4$ & $14.3 \pm 1.2$ & $14.3 \pm 1.2$ & $14.34 \pm 1.5$ & $14.2 \pm 1.3$ \\
\hline Creatinine $(\mu \mathrm{M})$ & $75 \pm 3$ & $78 \pm 6$ & $77 \pm 4$ & $76 \pm 4$ & $75 \pm 5$ \\
\hline Glucose (mM) & $4.9 \pm 0.4$ & $5.0 \pm 0.4$ & $5.2 \pm 0.3$ & $5.1 \pm 0.6$ & $4.8 \pm 0.4$ \\
\hline Lactate (mM) & $1.0 \pm 0.6$ & $1.2 \pm 1.4$ & $0.9 \pm 0.6$ & $1.1 \pm 0.7$ & $0.8 \pm 0.6$ \\
\hline \multicolumn{6}{|l|}{ Urine measurements ${ }^{\text {a }}$} \\
\hline $\mathrm{pH}$ & $6.4 \pm 0.5$ & $6.5 \pm 0.6$ & $6.8 \pm 0.5$ & $6.5 \pm 0.5$ & $6.5 \pm 0.4$ \\
\hline Specific gavity & $1.03 \pm 0.05$ & $1.01 \pm 0.01$ & $1.01 \pm 0.01$ & $1.01 \pm 0.01$ & $1.02 \pm 0.01$ \\
\hline
\end{tabular}

${ }^{*} \mathrm{p}=0.04$ against baseline total weight. All other variables were compared against baseline using a two-tailed paired Student's t-test. $\mathrm{P}>0.05$ in all cases.

a Urinary glucose, blood, leukocytes, nitrite, protein and urobilinogen levels were normal (not quantified). Data are means \pm standard deviation. 
Table 4

Fasting plasma metabolite concentrations before and after 28 days of drinking $3 \times 25 \mathrm{ml}$ ketone ester/day for 28 days $(n=24)$, a total of $2.1 \mathrm{~L}$ of ketone ester.

\begin{tabular}{lll}
\hline & Baseline & After 28 days \\
\hline Glucose (mM) & $4.9 \pm 0.4$ & $4.8 \pm 0.4$ \\
HOMA-IR & $0.7 \pm 0.4$ & $0.7 \pm 0.4$ \\
HbA1c (\%) & $5.5 \pm 0.4$ & $5.4 \pm 0.2^{*}$ \\
Triglycerides (mM) & $0.9 \pm 0.4$ & $0.9 \pm 0.4$ \\
Cholesterol (mM) & $4.8 \pm 1.0$ & $4.7 \pm 1.0$ \\
HDL (mM) & $1.6 \pm 0.3$ & $1.6 \pm 0.4$ \\
ApoB (mM) & $0.8 \pm 0.3$ & $0.8 \pm 0.2$ \\
C-reactive protein (mg/L) & $1.5 \pm 2.0$ & $0.9 \pm 1.1^{* *}$ \\
\hline
\end{tabular}

Data are means \pm standard deviations.

$* \mathrm{p}=0.02$ against baseline HbA1c

$* \mathrm{p}=0.01$ against baseline C-reactive protein.

All other variables were compared against baseline using a two-tailed paired Student's t-test. $\mathrm{P}>0.05$ for all.

Table 5

Adverse symptoms recorded by each participant $(n=24)$ following each of their 84 ketone drinks.

\begin{tabular}{llll}
\hline Symptom & No of participants & Intensity & Events $^{\mathrm{a}}$ \\
\hline Nausea & 4 & mild & $6 / 2,016$ \\
Upper abdominal pain & 2 & mild & $2 / 2,016$ \\
Diarrhoea & 2 & mild & $3 / 2,016$ \\
Headache & 1 & mild & $3 / 2,016$ \\
\hline
\end{tabular}

a Some participants recorded the same symptom more than once, so the occurrence was expressed relative to 2,016, the total number of drinks consumed $(24 \times 28 \times 3$ drinks). One participant reported more than one adverse symptom (nausea and upper abdominal pain) and one participant reported the same adverse symptom more than once (nausea).

any acute changes after the consumption of the ketone monoester drink must have been transitory and easily compensated (Stubbs et al., 2017).

Consistent with previous studies, adverse symptoms were infrequent, mild and mostly gastro-intestinal. (Clarke et al., 2012a; Stubbs et al., 2019). Indeed, there were no gastro-intestinal effects reported by athletes who consumed two ketone ester drinks per day for three weeks (Poffé et al., 2019).

This 28-day, "natural habitat" safety study is the longest that has been run on a ketone drink in healthy adults, although safety and tolerability were mentioned in a 20-month, case study of a patient with Alzheimer's disease (Newport et al., 2015). Here we report that an intake of $2.1 \mathrm{~L}$ of ketone monoester over 28 days resulted in a sustained ketosis that had no effect on physical or biochemical blood or urinary parameters in 24 healthy men and women aged between 18 and 70 years, whether athletic or sedentary, or consuming either a ketogenic or a normal, balanced diet.

\section{Funding}

Dr Adrian Soto Mota thanks the Consejo Nacional de Ciencia y Tecnología (CONACYT) and the Fundación para la Salud y Educación Dr Salvador Zubirán (FUNSAED) for support. Hannah Vansant thanks the Minority Health International Research Training (MHIRT) programme for her summer studentship. The ketone monoester, (R)-3-hydroxybutyl (R)-3-hydroxybutyrate, was provided for this study by $\mathrm{T} \Delta \mathrm{S}{ }^{\circledR} \mathrm{Ltd}$, Thame, UK.

\section{Declaration of competing interest}

The authors declare the following financial interests/personal relationships which may be considered as potential competing interests: The intellectual property covering the uses of ketone bodies and ketone esters are owned by BTG Plc, Oxford University Innovation Ltd and the US National Institutes of Health. Professor Kieran Clarke, as an inventor, will receive a share of the royalties under the terms prescribed by each institution. Professor Kieran Clarke is a director of TdeltaS Ltd, a company spun out of the University of Oxford to develop products based on the science of ketone bodies in human nutrition.

\section{Acknowledgements}

The authors thank the late Mrs Yvonne Green whose constant encouragement and enthusiasm made this study possible.

\section{References}

Clarke, K., Tchabanenko, K., Pawlosky, R., Carter, E., Knight, N.S., Murray, A.J., Cochlin, L.E., King, M.T., Wong, A.W., Roberts, A., Robertson, J., Veech, R.L., 2012. Oral 28-day and developmental toxicity studies of (R)-3-hydroxybutyl (R)-3-hydroxybutyrate. Regul. Toxicol. Pharmacol. 63, 196-208. doi:10.1016/j.yrtph.2012.04.001.

Clarke, K., Tchabanenko, K., Pawlosky, R., Carter, E., Todd King, M., Musa-Veloso, K., Ho, M., Roberts, A., Robertson, J., VanItallie, T.B., Veech, R.L., 2012. Kinetics, safety and tolerability of (R)-3-hydroxybutyl (R)-3-hydroxybutyrate in healthy adult subjects. Regul. Toxicol. Pharmacol. 63, 401-408. doi:10.1016/j.yrtph.2012.04.008.

Cox, P.J., Kirk, T., Ashmore, T., Willerton, K., Evans, R., Smith, A., Murray, A.J., Stubbs, B. West, J., McLure, S.W., King, M.T., Dodd, M.S., Holloway, C., Neubauer, S., Drawer, S., Veech, R.L., Giffin, J.L., Clarke, K., 2016. Nutritional ketosis alters fuel preference and thereby endurance performance in athletes. Cell Metabol. 24, 256-268. doi:10.1016/j.cmet.2016.07.010.

Gano, L.B., Patel, M., Rho, J.M., 2014. Ketogenic diets, mitochondria, and neurological diseases. J. Lipid Res. 55, 2211-2228. doi:10.1194/jlr.R048975.

Kemper, M.F., Srivastava, S., Todd King, M., Clarke, K., Veech, R.L., Pawlosky, R.J., 2015. An ester of $\beta$-hydroxybutyrate regulates cholesterol biosynthesis in rats and a cholesterol biomarker in humans. Lipids 50, 1185-1193. doi:10.1007/s11745-015-4085-x.

Kielb, S., Koo, H.P., Bloom, D.A., Faerber, G.J., 2000. Nephrolithiasis associated with the ketogenic diet. J. Urol. 164, 464-466. doi:10.1016/S0022-5347(05)67400-9.

Mizuno, Y., Harada, E., Nakagawa, H., Morikawa, Y., Shono, M., Kugimiya, F., Yoshimura, M., Yasue, H., 2017. The diabetic heart utilizes ketone bodies as an energy source. Metabolism 77, 65-72. doi:10.1016/j.metabol.2017.08.005.

Murray, A.J., Knight, N.S., Cole, M.A., Cochlin, L.E., Carter, E., Tchabanenko, K., Pichulik, T., Gulston, M.K., Atherton, H.J., Schroeder, M.A., Deacon, R.M.J., Kashiwaya, Y., King, M.T., Pawlosky, R., Rawlins, J.N.P., Tyler, D.J., Giffin, J.L., Robertson, J., Veech, R.L., Clarke, K., 2016. Novel ketone diet enhances physical and cognitive performance. FASEB J. 30, 4021-4032. doi:10.1096/fj.201600773R.

Newman, J.C., Verdin, E., 2014. $\beta$-hydroxybutyrate: much more than a metabolite. Diabetes Res. Clin. Pract. 106, 173-181. doi:10.1016/j.diabres.2014.08.009.

Newport, M.T., VanItallie, T.B., Kashiwaya, Y., King, M.T., Veech, R.L., 2015. A new way to produce hyperketonemia: use of ketone ester in a case of Alzheimer's disease. Alzheimer's Dementia 11, 99-103. doi:10.1016/j.jalz.2014.01.006.

Norwitz, N.G., Hu, M.T., Clarke, K., 2019. The mechanisms by which the ketone body D- $\beta$-hydroxybutyrate may improve the multiple cellular pathologies of Parkinson's disease. Front. Nutr. 6, 63. doi:10.3389/fnut.2019.00063.

Poffé, C., Ramaekers, M., Thienen, R., Hespel, P., 2019. Ketone ester supplementation blunts overreaching symptoms during endurance training overload. J. Physiol. 597, JP277831. doi:10.1113/JP277831.

Shivva, V., Cox, P.J., Clarke, K., Veech, R.L., Tucker, I.G., Duffull, S.B., 2016. The population pharmacokinetics of D- $\beta$-hydroxybutyrate following administration of (R)-3-hydroxybutyl (R)-3-hydroxybutyrate. AAPS J. 18, 678-688. doi:10.1208/ s12248-016-9879-0.

Stubbs, B.J., Cox, P.J., Evans, R.D., Santer, P., Miller, J.J., Faull, O.K., Magor-Elliott, S., Hiyama, S., Stirling, M., Clarke, K., 2017. On the metabolism of exogenous ketones in humans. Front. Physiol. 8, 848. doi:10.3389/fphys.2017.00848.

Stubbs, B.J., Cox, P.J., Kirk, T., Evans, R.D., Clarke, K., 2019. Gastrointestinal effects of exogenous ketone drinks are infrequent, mild and vary according to ketone compound and dose. Int. J. Sport Nutr. Exerc. Metab. 1-23. doi:10.1123/ijsnem.2019-0014.

Taggart, A.K.P., Kero, J., Gan, X., Cai, T.-Q., Cheng, K., Ippolito, M., Ren, N., Kaplan, R., Wu, K., Wu, T.-J., Jin, L., Liaw, C., Chen, R., Richman, J., Connolly, D., Offermanns, S., Wright, S.D., Waters, G.M., 2005. (D)-beta-Hydroxybutyrate inhibits adipocyte lipolysis via the nicotinic acid receptor PUMA-G. J. Biol. Chem. 280, 26649-26652. doi:10.1074/jbc.c500213200.

Veech, R.L., 2004. The therapeutic implications of ketone bodies: the effects of ketone bodies in pathological conditions: ketosis, ketogenic diet, redox states, insulin resistance, and mitochondrial metabolism. Prostagl. Leukot. Essent. Fat. Acids 70, 309-319. doi:10.1016/j.plefa.2003.09.007. 